\title{
Lifetime cumulative incidence of dementia in a community-dwelling elderly population in Japan
}

Daigo Yoshida, PhD, Tomoyuki Ohara, MD, PhD, Jun Hata, MD, PhD, Mao Shibata, MD, PhD, Yoichiro Hirakawa, MD, PhD, Takanori Honda, PhD, Yoshihiko Furuta, MD, PhD, Emi Oishi, MD, PhD, Satoko Sakata, MD, PhD, Shigenobu Kanba, MD, PhD, Takanari Kitazono, MD, PhD, and Toshiharu Ninomiya, MD, PhD

Neurology ${ }^{\circledR}$ 2020;95:e508-e518. doi:10.1212/WNL.0000000000009917

\section{Abstract \\ Objective}

To estimate the lifetime cumulative incidence of dementia and its subtypes from a communitydwelling elderly population in Japan.

\section{Methods}

A total of 1,193 community-dwelling Japanese individuals without dementia, aged 60 years or older, were followed up prospectively for 17 years. The cumulative incidence of dementia was estimated based on a death- and dementia-free survival function and the hazard functions of dementia at each year, which were computed by using a Weibull proportional hazards model. The lifetime risk of dementia was defined as the cumulative incidence of dementia at the point in time when the survival probability of the population was estimated to be less than $0.5 \%$.

\section{Results}

During the follow-up, 350 participants experienced some type of dementia; among them, 191 participants developed Alzheimer disease $(\mathrm{AD})$ and 117 developed vascular dementia $(\mathrm{VaD})$. The lifetime risk of dementia was 55\% (95\% confidence interval, 49\%-60\%). Women had an approximately 1.5 times greater lifetime risk of dementia than men (65\% [57\%-72\%] vs $41 \%$ [33\%-49\%]). The lifetime risks of developing $\mathrm{AD}$ and $\mathrm{VaD}$ were $42 \%(35 \%-50 \%)$ and $16 \%$ $(12 \%-21 \%)$ in women vs $20 \%(7 \%-34 \%)$ and $18 \%(13 \%-23 \%)$ in men, respectively.

\section{Conclusion}

Lifetime risk of all dementia for Japanese elderly was substantial at approximately 50\% or higher. This study suggests that the lifetime burden attributable to dementia in contemporary Japanese communities is immense.

\author{
Correspondence \\ Dr. Ninomiya \\ nino@ \\ eph.med.kyushu-u.ac.jp
}




\section{Glossary}

$\mathbf{A D}=$ Alzheimer disease $; \mathbf{C I}=$ confidence interval $\mathbf{D L B}=$ dementia with Lewy bodies; DSM-III-R = Diagnostic and Statistical Manual of Mental Disorders, 3rd edition, revised; HbAlc = hemoglobin A1c; HDS = Hasegawa Dementia Scale; HDS-R = Hasegawa Dementia Scale-Revised; MMSE = Mini-Mental State Examination; SD-NFT = senile dementia of the neurofibrillary tangle type; $\mathrm{VaD}=$ vascular dementia.

Dementia is a syndrome that affects memory, thinking, behavior, and the ability to perform everyday activities. According to the 2015 World Alzheimer Report, the number of people with dementia worldwide was estimated at 46.8 million in 2015 , and was expected to double to 74.7 million by 2030 and more than triple to 131.5 million by $2050 .{ }^{1}$ The global costs of dementia are enormous and inequitably distributed; the costs were estimated at $\$ 818$ billion USD in 2015 , and were expected to rise to $\$ 1$ trillion USD by 2018 , and to $\$ 2$ USD trillion by $2030{ }^{1,2}$ Dementia is widely acknowledged as a public health and social care priority worldwide.

Generally, epidemiologic studies have shown the incidence rate of dementia, which provides an estimate of dementia risk over a short period. On the other hand, the lifetime risk of dementia is defined as the cumulative probability of manifesting dementia over the rest of one's life, taking into account the competing risk of mortality. Estimating the lifetime risk of dementia in community-dwelling elderly populations would be helpful in order to evaluate the policy impact and the cost of health services. Whereas several prospective studies have reported the lifetime risk of dementia or Alzheimer disease in Western countries, ${ }^{3-11}$ no prospective study has investigated the lifetime risk of dementia in Asian populations. The purpose of this study was to clarify the lifetime probability of the development of dementia in a general Japanese population.

\section{Methods}

\section{Study population}

A population-based prospective study of cerebrocardiovascular diseases was established in 1961 in the town of Hisayama, a suburb of the Fukuoka metropolitan area on Japan's Kyushu Island. Surveys of the neurologic conditions and health status of residents aged 40 years or older have been repeated since $1961 .{ }^{12,13}$ In addition, comprehensive surveys of cognitive function, including neuropsychological tests, have been carried out on the elderly every 6 or 7 years since $1985 .{ }^{14}$ In 1988, a total of 1,228 residents aged 60 years or older (89.9\% of the total population in this age group) participated in a health checkup. After excluding 31 participants with dementia at baseline and 4 participants who died before starting the follow-up, the remaining 1,193 (696 women and 497 men) were enrolled in this study. Written informed consent was obtained from the participants. This study was conducted with the approval of the ethics committee of the Kyushu University Faculty of Medicine.

\section{Follow-up survey}

The participants were followed up for 17 years prospectively, from December 1988 to November 2005. Details about the follow-up survey on dementia have been described in our previous reports. ${ }^{15,16}$ Follow-up screening surveys of cognitive function, including neuropsychological tests, the Hasegawa Dementia Scale (HDS), ${ }^{17}$ the Hasegawa Dementia Scale-Revised (HDS-R), ${ }^{18}$ or the Mini-Mental State Examination (MMSE), ${ }^{19}$ were conducted in 1992, 1998, and 2005. All the participation rates of these surveys were over $90 \%$. Letters or telephone calls were used to collect the health information of participants who did not undergo examinations or who had moved away from the town. ${ }^{20}$ We also established a system of daily monitoring that was conducted by the study team, members of the town's Health and Welfare Office, or local physicians to collect information about new events, including stroke, cognitive impairment, and dementia. When a participant was suspected of having new neurologic symptoms, including cognitive impairment, he or she was evaluated carefully by stroke physicians and psychiatrists of the study team. We conducted a comprehensive investigation that included interviews of his or her family or attending physician, physical and neurologic examinations including assessment of functional capacity (activities of daily living and instrumental activities of daily living), and a review of the clinical records. Furthermore, when a participant died, we checked all the available clinical information, interviewed the attending physician and family of the deceased, and tried to obtain permission for an autopsy from the family. During the follow-up period, 615 participants (53.2\% of the participants enrolled in the study) died, and autopsies were performed in $464(75.5 \%)$ participants. The mean age at death in autopsied cases was 83.5 years (SD 7.9).

\section{Diagnosis of dementia}

Because several factors (e.g., low education or hearing loss) can cause overdiagnosis of cognitive impairment by the neuropsychological tests, ${ }^{21}$ we performed 2 -step procedures for the diagnosis of dementia. ${ }^{14}$ First, trained physicians or nurses performed the neuropsychological tests. When the test scores were below the cutoff points of $22 / 32.5$ for the HDS ${ }^{17}$ or $21 / 30$ for the HDS- $\mathrm{R}^{18}$ and MMSE, ${ }^{19}$ or when new neurologic symptoms including cognitive impairment were suspected, the participant was evaluated carefully by the neurologists and psychiatrists, who conducted comprehensive investigations such as interviews of the family or physical and neurologic examinations including assessment of functional capacity (activities of daily living and instrumental activities of 
daily living). In addition, study physicians including neurologists and psychiatrists visited medical institutions to review any available clinical records for each suspected dementia case. Diagnoses of dementia and its subtypes were based on the guidelines of the DSM-III-R, ${ }^{22}$ the criteria of the National Institute of Neurologic and Communicative Disorders and Stroke and the Alzheimer's Disease and Related Disorders Association, ${ }^{23}$ and the criteria of the National Institute of Neurologic Disorders and Stroke-Association Internationale pour la Recherche et l'Enseignement en Neurosciences. ${ }^{24}$ Every dementia case was diagnosed by 2 or more expert neurologists and psychiatrists. Possible or probable dementia subtypes were adjudicated with clinical information including neuroimaging. Definite dementia subtypes were also determined on the basis of clinical and neuropathologic information in deceased participants with dementia who underwent autopsy. The diagnostic procedure for autopsy cases has been reported elsewhere. ${ }^{25}$ A neuropathologic diagnosis of Alzheimer disease (AD) was made following the National Institute on Aging-Reagan Institute criteria, ${ }^{26}$ where the frequencies of senile plaques and neurofibrillary tangles were evaluated using the criteria of the Consortium to Establish a Registry for Alzheimer's Disease ${ }^{27}$ and the Braak stage. ${ }^{28}$ Definite vascular dementia $(\mathrm{VaD})$ cases were confirmed with a causative stroke or cerebrovascular change. Dementia with Lewy bodies (DLB) was diagnosed based on the revised consensus guidelines described in the third report of the DLB Consortium. ${ }^{29}$ According to the DLB Consortium guidelines, dementia cases meeting the "high likelihood" criterion of DLB pathology are defined as definite DLB. Senile dementia of the neurofibrillary tangle type (SD-NFT; tangle only dementia) was diagnosed neuropathologically using the Yamada guideline, ${ }^{30}$ and a diagnosis of argyrophilic grain disease was diagnosed based on staging of argyrophilic grains. ${ }^{31}$
During the 17-year follow-up period, 350 participants developed dementia. Of these, 317 participants in all (90.6\%) underwent some kind of morphologic examination: 300 (85.7\%) underwent evaluation with neuroimaging and 184 (52.6\%) received a general autopsy examination; in 167 cases, both were performed. Thus, 184 dementia cases were classified as definite subtypes, and 166 dementia cases as probable/ possible subtypes. Among dementia cases, $29 \mathrm{AD}$ cases and 24 $\mathrm{VaD}$ cases had other coexisting subtypes of dementia, and 18 of these cases were a mixed type of $\mathrm{AD}$ and $\mathrm{VaD}$. These cases were counted as events in the analysis for each subtype.

\section{Risk factors}

At the baseline examination, each participant completed a self-administered questionnaire covering educational status, medical history, antihypertensive treatment, smoking habits, alcohol intake, and physical activity. A low educational level was defined as 6 or fewer years of formal education. Smoking habits and alcohol consumption were classified as either current use or not. Regular exercise was defined as engaging in exercise at least 3 or more times a week during leisure time. Sitting blood pressure was measured with a mercury sphygmomanometer 3 times at the right upper arm after at least 5 minutes of rest, and the mean of the 3 measurements was used in the analysis. Hypertension was determined as blood pressure $\geq 140 / 90 \mathrm{~mm} \mathrm{Hg}$ or the use of antihypertensive agents. Body height and weight were measured in light clothing without shoes, and body mass index $\left(\mathrm{kg} / \mathrm{m}^{2}\right)$ was calculated. Diabetes was defined by fasting glucose concentrations $\geq 7.0$ $\mathrm{mmol} / \mathrm{L}$, 2-hour postload or postprandial glucose concentrations $\geq 11.1 \mathrm{mmol} / \mathrm{L}$, or use of glucose-lowering agents. Hemoglobin Alc ( $\mathrm{HbAlc}$ ) was measured by high-pressure liquid chromatography. The value for $\mathrm{HbAlc}$ was corrected to the National Glycohemoglobin Standardization Program

Figure 1 Observed cumulative hazard plots for the occurrence of all dementia and the occurrence of death or all dementia

A. All dementia

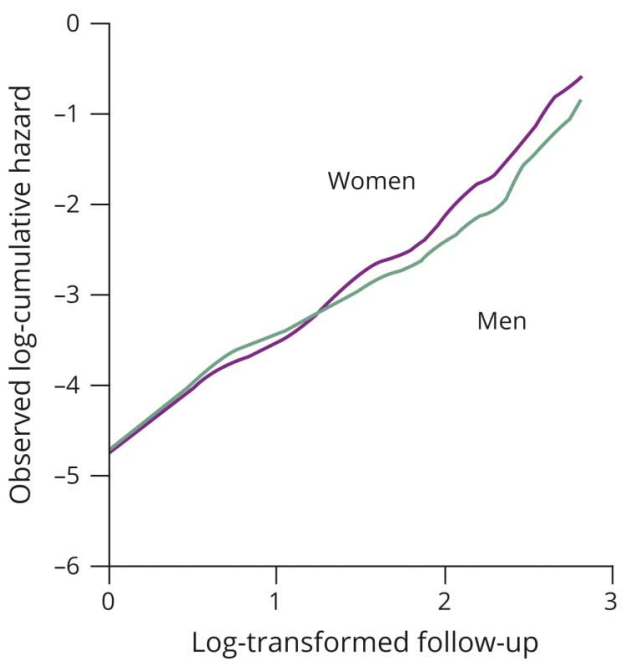

B. Death or all dementia

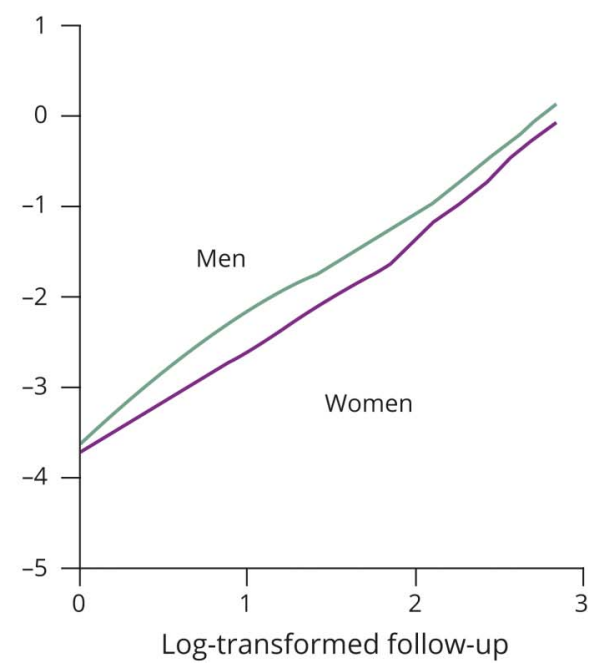

(A) All dementia. (B) Death or all dementia. 
equivalent value (\%) with the following formula: $\mathrm{HbAlc}$ (\%) $=1.02 \times \mathrm{HbAlc}(\%)+0.25 \%$. Serum total cholesterol and high-density lipoprotein cholesterol levels were measured by the enzymatic method. History of stroke was defined on the basis of all clinical data available in the Hisayama Study. Electrocardiogram abnormalities were defined as left ventricular hypertrophy (Minnesota Code, 3-1), ST depression (4-1, 2, 3), or atrial fibrillation (8-3).

\section{Statistical analysis}

The software package SAS (version 9.4; SAS Institute, Cary, NC) was used to perform all statistical analyses. The cumulative incidence of dementia and its subtypes was calculated taking the presence of competing risks of death into consideration (figure e-1, doi.org/10.5061/dryad. $\mathrm{d} 8 \mathrm{v} 1 \mathrm{~b} 44) .{ }^{32}$ First, we estimated the death- and all dementiafree survival probabilities, and all dementia-free survival probabilities during follow-up by using the usual KaplanMeier methods, then generated cumulative hazard plots in order to check the distribution of survival probabilities. The plots of log-transformed cumulative hazards vs logtransformed follow-up times resembled straight lines for either sex (figure 1), suggesting that a Weibull distribution was appropriate for the distribution of survival time for these

Table 1 Baseline characteristics of the study population

\begin{tabular}{|c|c|c|c|}
\hline & Women & Men & $p$ Value \\
\hline No. of participants & 696 & 497 & \\
\hline Age, y & $70.9(7.4)$ & $69.8(7.1)$ & 0.01 \\
\hline Age categories, y & & & 0.22 \\
\hline 60-69 & 49.6 & 54.9 & \\
\hline 70-79 & 36.1 & 33.0 & \\
\hline $80-89$ & 13.4 & 11.7 & \\
\hline 90 years or older & 1.0 & 0.4 & \\
\hline Education $\leq 6$ years & 20.8 & 7.4 & $<0.0001$ \\
\hline Systolic blood pressure, mm Hg & $142.0(24.1)$ & $139.4(22.5)$ & 0.06 \\
\hline Diastolic blood pressure, $\mathrm{mm} \mathrm{Hg}$ & $75.2(10.7)$ & $77.9(10.7)$ & $<0.0001$ \\
\hline Hypertension & 57.2 & 55.9 & 0.67 \\
\hline Antihypertensive medication & 26.9 & 23.7 & 0.22 \\
\hline Hemoglobin A1c & $5.7(0.8)$ & $5.7(0.8)$ & 0.49 \\
\hline Diabetes & 13.7 & 14.7 & 0.61 \\
\hline Total cholesterol, $\mathrm{mmol} / \mathrm{L}$ & $5.7(1.1)$ & $5.0(1.1)$ & $<0.0001$ \\
\hline High-density lipoprotein cholesterol, mmol/L & $1.3(0.3)$ & $1.2(0.3)$ & 0.045 \\
\hline Body mass index, $\mathrm{kg} / \mathrm{m}^{2}$ & $22.4(3.4)$ & $21.9(2.9)$ & 0.002 \\
\hline Electrocardiogram abnormalities, \% & 20.6 & 23.9 & 0.16 \\
\hline History of stroke & 4.7 & 6.8 & 0.12 \\
\hline Smoking habit & 7.0 & 45.7 & $<0.0001$ \\
\hline Alcohol intake & 7.1 & 49.2 & $<0.0001$ \\
\hline Regular exercise & 12.2 & 17.5 & 0.01 \\
\hline All dementia during follow-up & $234(33.6)$ & $116(23.3)$ & 0.0001 \\
\hline AD during follow-up & $149(21.4)$ & $42(8.5)$ & $<0.0001$ \\
\hline VaD during follow-up & $60(8.6)$ & 57 (11.5) & 0.10 \\
\hline
\end{tabular}

Abbreviations: $\mathrm{AD}=$ Alzheimer disease; $\mathrm{VaD}=$ vascular dementia

Values were represented as mean (SD), \%, or $n(\%)$.

Hypertension was defined as blood pressure $\geq 140 / 90 \mathrm{~mm} \mathrm{Hg}$ or use of antihypertensive medication. Diabetes was defined as fasting blood glucose $\geq 7.0$ $\mathrm{mmol} / \mathrm{L}$, casual or postload blood glucose $\geq 11.1 \mathrm{mmol} / \mathrm{L}$, or use of glucose-lowering agents. Electrocardiogram abnormalities were defined as left ventricular hypertrophy (Minnesota code, 3-1), ST depression (Minnesota code, 4-1, 2, 3), or atrial fibrillation (Minnesota code, 8-3-1). Regular exercise was defined as engaging in sports at least 3 times per week during leisure time. 
endpoints. Therefore, we built a function to describe deathand all dementia-free survival (eS[t]), and a function to describe all dementia (or each dementia subtype)-free survival ( $\mathrm{eS}^{\prime}[\mathrm{t}]$ ) by using the Weibull proportional hazard model, where $t$ is years of follow-up. The number of participants at risk for each year of follow-up $(\mathrm{eN}[\mathrm{t}])$ was calculated as $\mathrm{eN}(\mathrm{t})=$ $\mathrm{eN}(0) \times \mathrm{eS}(\mathrm{t})$. The cumulative hazard function $\left(\mathrm{eCH}^{\prime}[\mathrm{t}]\right)$ and the hazard function $\left(\mathrm{eH}^{\prime}[\mathrm{t}]\right)$ of incident all dementia (or each dementia subtype) were computed as $\mathrm{eCH}^{\prime}(\mathrm{t})=-\log \left(\mathrm{eS}^{\prime}[\mathrm{t}]\right)$ and $\mathrm{eH}^{\prime}(\mathrm{t})=\mathrm{eCH}^{\prime}(\mathrm{t})-\mathrm{eCH}^{\prime}(\mathrm{t}-1)$, respectively. On the basis of these functions, the cumulative incidence of all dementia or each dementia subtype (unit: percentage) at each year was estimated as $\mathrm{eCI}(\mathrm{t})=\sum\left(\mathrm{eN}[\mathrm{t}-1] \times \mathrm{eH}^{\prime}[\mathrm{t}]\right) / \mathrm{N}(0) \times 100$. The agreement between the observed and estimated cumulative incidence was assessed using an intraclass correlation coefficient for one-way random single measures. ${ }^{33}$ The estimated lifetime risk of all dementia (or each dementia subtype) was defined as the estimated cumulative incidence of the relevant endpoint at the years that the estimated frequency of participants at risk reached less than $0.5 \%{ }^{34}$ The $95 \%$ confidence intervals (CIs) of estimated cumulative incidence were estimated from 1,000 bootstrap samples.

\section{Standard protocol approvals, registrations, and patient consents}

This study was approved by the Kyushu University Institutional Review Board for Clinical Research. We obtained written informed consent from all participants.

\section{Data availability}

The datasets generated and analyzed in the present study are not publicly available because they contain confidential clinical and demographic data of the study participants. However, further information about the datasets is available with the permission of the principal investigator of the Hisayama Study (Toshiharu Ninomiya) on reasonable request for purposes of replicating procedures and results.

\section{Results}

During the follow-up, 191 participants (92 autopsy cases) developed $\mathrm{AD}, 117$ (77 autopsy cases) developed $\mathrm{VaD}$, and 60 (30 autopsy cases) developed other subtypes of dementia. The other subtypes of dementia included 60 cases of the following subtypes: 16 cases (13 autopsy cases) of DLB, 9 cases ( 9 autopsy cases) of SD-NFT, 1 case ( 1 autopsy case) of progressive supranuclear palsy, 2 cases (2 autopsy cases) of argyrophilic grain disease, 6 cases (2 autopsy cases) of frontotemporal lobar degeneration, 1 case (0 autopsy cases) of hypoxic ischemic encephalopathy, 1 case (1 autopsy case) of brain tumor, 1 case ( 1 autopsy case) of hypothyroidism, 1 case (0 autopsy cases) of alcohol-induced dementia, 6 cases $(0$ autopsy cases) of head injury-induced dementia, and 16 cases ( 1 autopsy case) of unknown cause. The baseline characteristics of the study population according to sex are shown in table 1. The mean age was 69.8 years (SD 7.1) in men and 70.9 years (SD 7.4) in women. The mean values of diastolic blood pressure and frequencies of smoking habits, alcohol intake, and regular exercise were higher in men than in women. Conversely, the mean values of total cholesterol, high-density lipoprotein cholesterol, body mass index, and low education were lower in men than in women.

Figure 2 shows the observed and estimated proportional rates of death and all dementia-free survival $(\mathrm{eS}[\mathrm{t}]$, figure $2 \mathrm{~A})$ and all dementia-free survival $\left(\mathrm{eS}^{\prime}[\mathrm{t}]\right.$, figure $2 \mathrm{~B}$ ) during the follow-up. The proportional rates of all dementia-free survival for 17 years were 0.762 in men and 0.657 in women. In addition, the rates of survival without developing dementia were 0.326 in men and 0.392 in women. Based on these timeto-event data, the estimated proportional rates of all dementia-free survival were $\exp \left(-0.0024 \times\right.$ Year $\left.^{1.9129}\right)$ for women and $\exp \left(-0.0022 \times\right.$ Year $\left.^{1.8407}\right)$ for men. Moreover, the estimated proportional rates of death and all dementiafree survival were $\exp \left(-0.0091 \times\right.$ Year $\left.^{1.6351}\right)$ for women and

Figure 2 Observed and estimated proportional rate of death- and all dementia-free survival and all dementia-free survival

A. Death-and all dementia-free

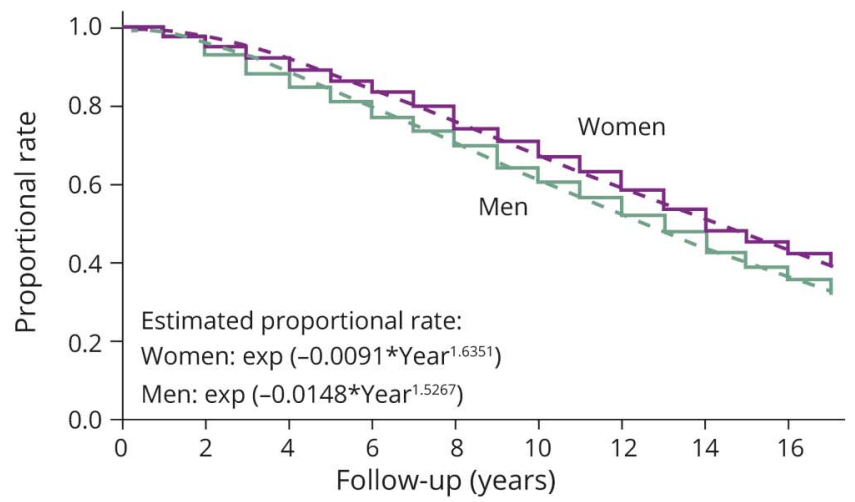

B. All dementia-free

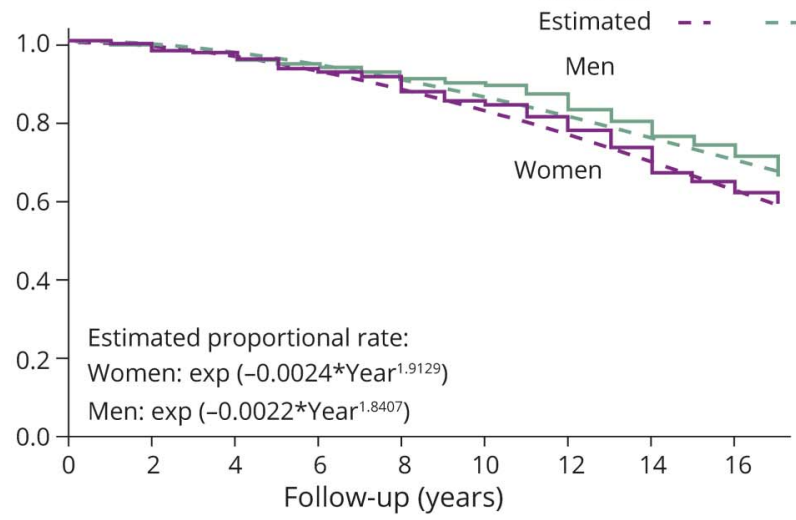

(A) Death- and all dementia-free survival. (B) All dementia-free survival. Time 0 represents the time of the initiation of follow-up (baseline survey). 
Table 2 Calculation of estimated cumulative incidence of all dementia during the follow-up period

\begin{tabular}{|c|c|c|c|c|c|}
\hline Year (t) & $\begin{array}{l}\text { Estimated proportional } \\
\text { rate of death- and all } \\
\text { dementia-free survival } \\
(\mathrm{eS}[\mathrm{t}])^{\mathrm{a}}\end{array}$ & $\begin{array}{l}\text { Estimated number } \\
\text { of participants at } \\
\text { risk }(e N[t]=e S[t] \times \\
\text { eN[0]) }\end{array}$ & $\begin{array}{l}\text { Estimated annual } \\
\text { incidence rate of all } \\
\text { dementia }\left(e H^{\prime}[t]=\mathrm{eCH}^{\prime}\right. \\
[\mathrm{t}]-\mathrm{eCH}[\mathrm{t}-1])^{\mathrm{b}}\end{array}$ & $\begin{array}{l}\text { Estimated cumulative } \\
\text { number of incident all } \\
\text { dementia }\left(\sum \mathrm{eE}[\mathrm{t}]=\sum[\mathrm{eN}(\mathrm{t}\right. \\
\left.\left.-1) \times \mathrm{eH}^{\prime}(\mathrm{t})\right]\right)\end{array}$ & $\begin{array}{l}\text { Estimated cumulative } \\
\text { incidence of all } \\
\text { dementia, \% }(\mathrm{eCl}[\mathrm{t}]= \\
\left.\sum \mathrm{eE}[\mathrm{t}] / \mathrm{N}[0] \times 100\right)\end{array}$ \\
\hline \multicolumn{6}{|l|}{ Women } \\
\hline 0 & 1.000 & 696 & & & 0.0 \\
\hline 1 & 0.991 & 690 & 0.002 & 1.6 & 0.2 \\
\hline 2 & 0.972 & 677 & 0.007 & 6.1 & 0.9 \\
\hline 3 & 0.947 & 659 & 0.010 & 13.2 & 1.9 \\
\hline 4 & 0.916 & 637 & 0.014 & 22.5 & 3.2 \\
\hline 5 & 0.881 & 613 & 0.018 & 33.8 & 4.9 \\
\hline 6 & 0.843 & 587 & 0.021 & 46.9 & 6.7 \\
\hline 7 & 0.803 & 559 & 0.025 & 61.5 & 8.8 \\
\hline 8 & 0.761 & 530 & 0.028 & 77.4 & 11.1 \\
\hline 9 & 0.718 & 500 & 0.032 & 94.2 & 13.5 \\
\hline 10 & 0.675 & 470 & 0.035 & 111.8 & 16.1 \\
\hline 11 & 0.632 & 440 & 0.039 & 129.9 & 18.7 \\
\hline 12 & 0.589 & 410 & 0.042 & 148.3 & 21.3 \\
\hline 13 & 0.547 & 381 & 0.045 & 166.9 & 24.0 \\
\hline 14 & 0.506 & 352 & 0.048 & 185.3 & 26.6 \\
\hline 15 & 0.467 & 325 & 0.052 & 203.6 & 29.2 \\
\hline 16 & 0.429 & 298 & 0.055 & 221.4 & 31.8 \\
\hline 17 & 0.392 & 273 & 0.058 & 238.8 & 34.3 \\
\hline \multicolumn{6}{|l|}{ Men } \\
\hline 0 & 1.000 & 497 & & & 0.0 \\
\hline 1 & 0.985 & 490 & 0.002 & 1.1 & 0.2 \\
\hline 2 & 0.958 & 476 & 0.006 & 3.9 & 0.8 \\
\hline 3 & 0.924 & 459 & 0.009 & 8.0 & 1.6 \\
\hline 4 & 0.884 & 439 & 0.012 & 13.3 & 2.7 \\
\hline 5 & 0.841 & 418 & 0.014 & 19.6 & 3.9 \\
\hline 6 & 0.796 & 395 & 0.017 & 26.6 & 5.4 \\
\hline 7 & 0.749 & 372 & 0.019 & 34.3 & 6.9 \\
\hline 8 & 0.701 & 349 & 0.022 & 42.4 & 8.5 \\
\hline 9 & 0.654 & 325 & 0.024 & 50.9 & 10.2 \\
\hline 10 & 0.607 & 302 & 0.027 & 59.6 & 12.0 \\
\hline 11 & 0.562 & 279 & 0.029 & 68.4 & 13.8 \\
\hline 12 & 0.518 & 257 & 0.031 & 77.1 & 15.5 \\
\hline 13 & 0.475 & 236 & 0.034 & 85.8 & 17.3 \\
\hline 14 & 0.435 & 216 & 0.036 & 94.3 & 19.0 \\
\hline
\end{tabular}


Table 2 Calculation of estimated cumulative incidence of all dementia during the follow-up period (continued)

\begin{tabular}{|c|c|c|c|c|c|}
\hline Year $(t)$ & $\begin{array}{l}\text { Estimated proportional } \\
\text { rate of death- and all } \\
\text { dementia-free survival } \\
(\mathrm{eS}[\mathrm{t}])^{\mathrm{a}}\end{array}$ & $\begin{array}{l}\text { Estimated number } \\
\text { of participants at } \\
\text { risk }(e N[t]=e S[t] \times \\
\text { eN[0]) }\end{array}$ & $\begin{array}{l}\text { Estimated annual } \\
\text { incidence rate of all } \\
\text { dementia }\left(e \mathrm{eH}^{\prime}[\mathrm{t}]=\mathrm{eCH}^{\prime}\right. \\
[\mathrm{t}]-\mathrm{eCH}[\mathrm{t}-1])^{\mathbf{b}}\end{array}$ & $\begin{array}{l}\text { Estimated cumulative } \\
\text { number of incident all } \\
\text { dementia }\left(\sum \mathrm{eE}[\mathrm{t}]=\sum[\mathrm{eN}(\mathrm{t}\right. \\
\left.\left.-1) \times \mathrm{eH}^{\prime}(\mathrm{t})\right]\right)\end{array}$ & $\begin{array}{l}\text { Estimated cumulative } \\
\text { incidence of all } \\
\text { dementia, } \%(\mathrm{eCl}[\mathrm{t}]= \\
\left.\sum \mathrm{eE}[\mathrm{t}] / \mathrm{N}[0] \times 100\right)\end{array}$ \\
\hline 15 & 0.396 & 197 & 0.038 & 102.5 & 20.6 \\
\hline 16 & 0.360 & 179 & 0.040 & 110.5 & 22.2 \\
\hline 17 & 0.326 & 162 & 0.043 & 118.1 & 23.8 \\
\hline
\end{tabular}

a The function eS(t) represents the estimated proportional rate of death- and dementia-free survival for year $t$ of follow-up: eS(t) $=\exp \left(-0.0091 \times t^{1.6351}\right)$ for women and $\exp \left(-0.0148 \times \mathrm{t}^{1.5267}\right)$ for men.

${ }^{b}$ The function $\mathrm{eCH}^{\prime}(\mathrm{t})$ represents the estimated cumulative hazard of dementia for follow-up period $t: e C \mathrm{H}^{\prime}(\mathrm{t})=-\log \left(\mathrm{e} \mathrm{S}^{\prime}[\mathrm{t}]\right)=0.0024 \times \mathrm{t}^{1.9129}$ for women and $0.0022 \times \mathrm{t}^{1.8407}$ for men, where $\mathrm{eS}^{\prime}(\mathrm{t})$ is the estimated proportional rate of dementia-free survival for year $\mathrm{t}$ of follow-up.

$\exp \left(-0.0148 \times\right.$ Year $\left.^{1.5267}\right)$ for men. As shown in table 2, the estimated cumulative incidence rates of all dementia were calculated by using these formulas. The observed and estimated cumulative incidence rates of all dementia for 17 years were compared by sex (figure e-2, doi.org/10.5061/dryad. $\mathrm{d} 8 \mathrm{v} 1 \mathrm{~b} 44)$. For both men and women, the observed and estimated cumulative incidence rates of dementia were wellfitted. The intraclass correlation coefficient was 0.996 for women and 0.985 for men.

The sex-specific lifetime risks of all dementia and its subtypes were computed by using the aforementioned formulas in a general population of elderly Japanese participants. Estimated lifetime risk of all dementia was 64.8\% (95\% CI, $57.4 \%-72.1 \%)$ for women and $40.8 \%$ (95\% CI, $33.0 \%-48.5 \%$ ) for men (figure 3). In the overall study population, 54.8\% (95\% CI, 49.4-60.1) of participants aged 60 years would be presumed to develop some type of dementia during the remainder of their lives. With regard to subtypes of dementia, the lifetime risk of $\mathrm{AD}$ for women was estimated to be approximately 2 -fold higher than that for men $(42.4 \%$ [95\% CI, 35.1\%-49.7\%] for women; $20.4 \%$ [95\% CI, $6.6 \%-34.2 \%]$ for men), whereas the estimated lifetime risk of $\mathrm{VaD}$ was similar between the sexes $(16.3 \%$ [95\% CI, $11.5 \%-21.1 \%$ ] for women; $17.8 \%$ [ $95 \% \mathrm{CI}, 12.9 \%-22.7 \%]$ for men) (figure 4).

\section{Discussion}

The present study clearly demonstrated that the lifetime risk of all dementia was more than $50 \%$ in a general population of Japanese participants aged 60 years or older. Women had a higher lifetime risk of dementia, especially $\mathrm{AD}$, than men. To our knowledge, this is the first study addressing the lifetime risk of dementia in a general elderly population in an Asian region. Several prospective studies have reported that the lifetime risks of dementia or $\mathrm{AD}$ varied from $14.3 \%$ to $49.6 \%$ in the populations studied. ${ }^{3-11}$ As expected, these estimates were substantially lower than our estimates. These discrepancies may have arisen from differences in the demographic characteristics of the study populations, such as the age distribution or life expectancy, because individuals in populations with a shorter life expectancy or a higher mortality rate from other causes, such as cardiovascular disease or cancer, would be likely to die before the onset of dementia. ${ }^{15}$ Japan has one of the highest life expectancies worldwide, ${ }^{35}$ and thus the Japanese are likely to have a greater risk of dementia in their lifespans. In addition, the high incidence of dementia in our study may have been related to the accuracy of the dementia survey used. A high study participation rate and follow-up rate are important to accurately determine the incidence of dementia, because low participation rates lead to the healthy screening bias, which could cause an underestimation of the incidence of dementia. For example, the previous studies reported that nonparticipating elderly had more mild cognitive impairment and dementia than their participating elderly counterparts. ${ }^{36,37}$ In the present study, underestimation of the incidence of dementia was unlikely to have occurred, because full community surveys that included patients staying in the hospital or health care facilities during follow-up were performed. Some combination of the above phenomena could explain why the lifetime risk of dementia in the present study was so much higher than the estimates reported previously in other geographically or ethnically different populations. On the other hand, the average life expectancy of Japanese people increased by about 6 years between 1988 and 2018 for both men and women $(75.5$ years in 1988 vs 81.3 years in 2018 for men, 81.3 years vs 87.3 years for women). A previous study reported that the incidence of dementia in community-dwelling Japanese increased from 1988 to $2002 .{ }^{14}$ Therefore, the current cumulative incidence of dementia in Japanese elderly is likely higher than that estimated in the present study.

The present study showed that women had an approximately 2 -fold greater lifetime risk of $\mathrm{AD}$ than men. The exact reasons underlying the sex difference in the risk of dementiaparticularly $\mathrm{AD}$ - are unclear, but possible explanations are as follows. First, women have a longer life expectancy than men in Japan. In 2018, the life expectancy of Japanese people was 81.1 years for men and 87.3 years for women, a difference of 
Figure 3 Estimated lifetime risks of all dementia in the elderly by sex
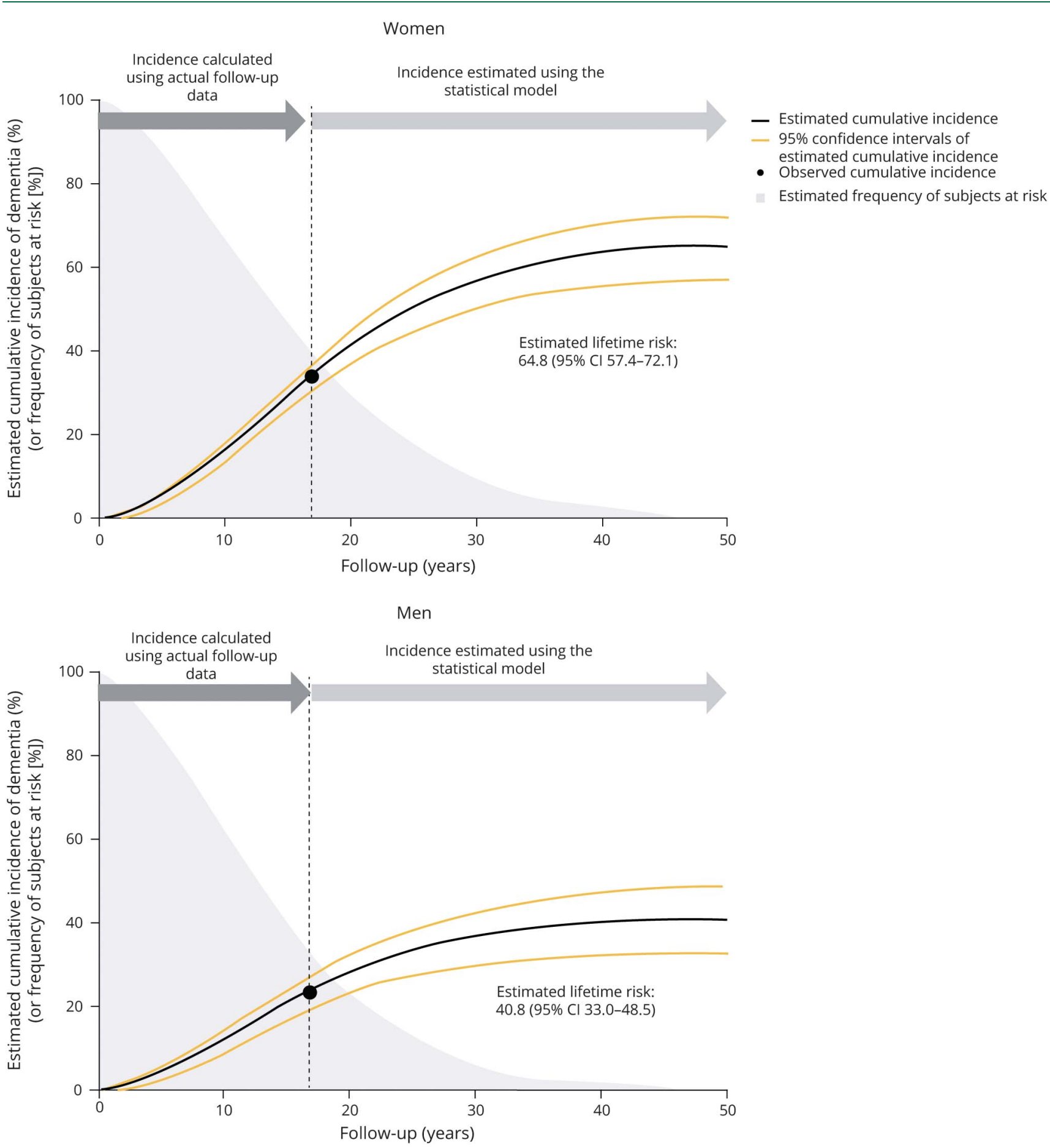

Estimated remaining lifetime risk of all dementia was defined as the estimated cumulative incidence of all dementia over the years of follow-up for which the estimated frequency of participants at risk reached less than $0.5 \%$. Time 0 represents the time of the initiation of follow-up (baseline survey). $\mathrm{Cl}=\mathrm{confidence}$ interval.

about 6 years. Second, women had less regular exercise and lower education than men in this study. Moreover, there were few opportunities for social activity for women in Japan in the 1980s. ${ }^{38}$ Physical inactivity, social isolation, and low education are all considered important risk factors for dementia according to the recent WHO guidelines. ${ }^{39}$ Finally, the sex difference in the influence of $A P O E \varepsilon 4$ on dementia risk may have partially contributed to the discrepancy in the incidence of $A D$ between the sexes. ${ }^{40}$ Several studies have reported that the $A P O E \& 4$ risk for $\mathrm{AD}$ is greater in women. ${ }^{41,42}$ Any of these facts, either singly or in combination, could have accounted for the higher prevalence of $\mathrm{AD}$ and other dementia 


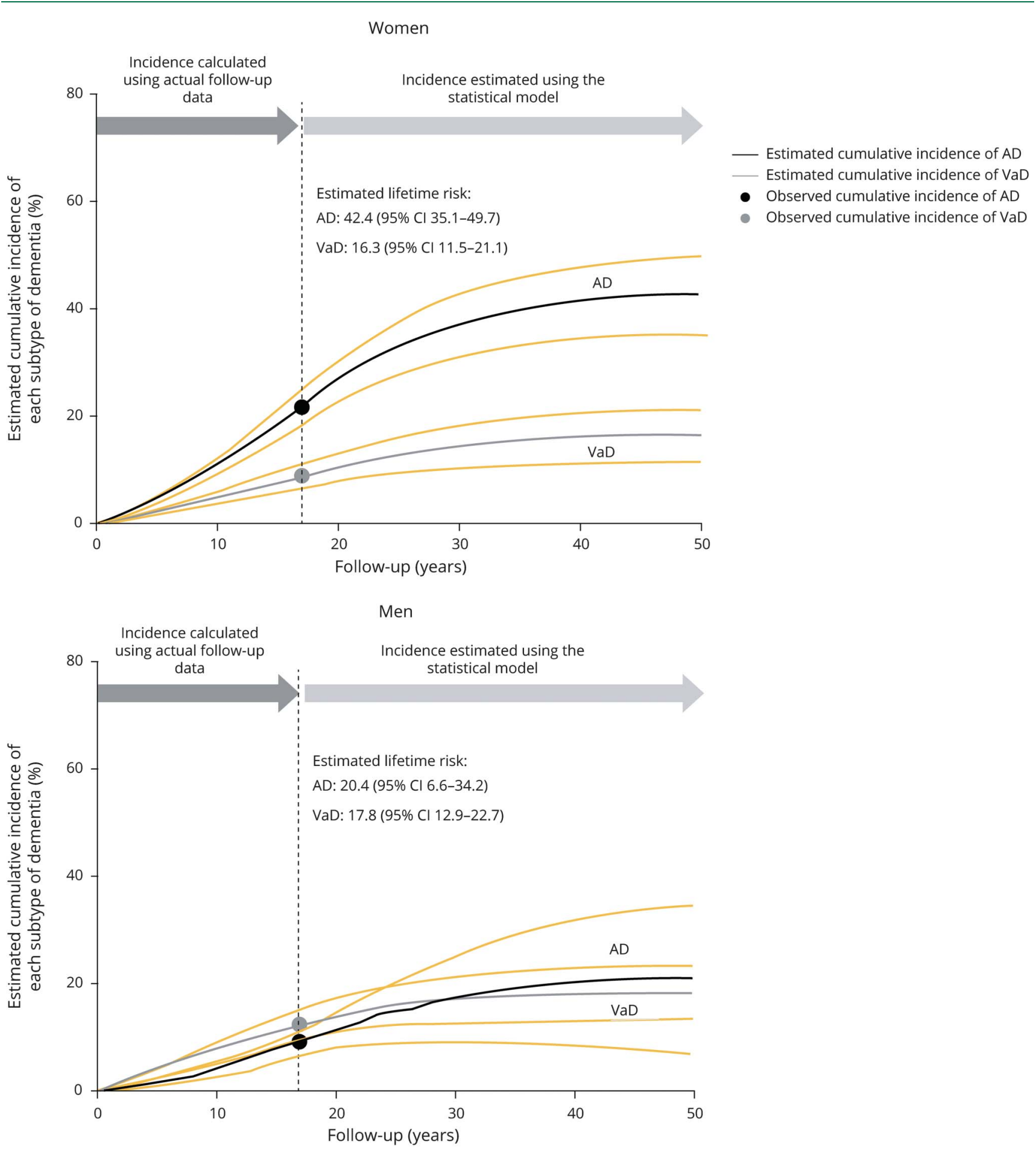

Time 0 represents the time of the initiation of follow-up (baseline survey). $\mathrm{Cl}=$ confidence interval.

in women. Conversely, in a report from the American Heart Association Conference, the lifetime risk of $\mathrm{VaD}$ was found to be similar between sexes, even though men were likely to have a higher risk of cerebrovascular diseases than women. ${ }^{43}$ This may be because the excess risk of cerebrovascular diseases in men was offset by their shorter life expectancy. In addition, the improved management of risk factors of $\mathrm{VaD}$ such as hypertension and smoking habits may reduce the lifetime risk of $\mathrm{VaD}$ in men.
The strengths of our study include the longitudinal population-based design, the long follow-up period, the complete follow-up of the participants, and the availability of neuropathology and neuroimaging data to determine dementia subtypes. In addition, we used both data on the incidence of dementia and data on mortality from the same population so that we could consider the effects of competing risk. Some limitations should also be noted. First, the validity 
of the estimated survival curve and annual incidence rate of dementia was limited after 18 years of follow-up. However, about two-thirds of the study population had already died or developed dementia by 17 years of follow-up, which may be a sufficient number to build statistical models for estimating participants at risk for and incidence of dementia at each time point of the follow-up period, and the estimated probabilities of dementia were in excellent agreement with the observed ones in both sexes. Therefore, the influence of this limitation on our findings would be modest. Second, we were unable to estimate the lifetime risk of dementia according to age groups due to the limited sample size; such data would also be valuable for policy makers. Third, there was a possibility of overdiagnosis of dementia due to low education or hearing loss, especially during the process of estimating cognitive function in neuropsychological tests. Therefore, the study physician and psychiatrist conducted detailed examinations including interviews of the family, attending physician, and staff of the Division of Health and Welfare of the Hisayama town for all the cases suspicious for dementia based on the neuropsychological tests, and we also conducted examinations in writing for participants with hearing loss to avoid overdiagnosis as much as possible. Fourth, the diagnosis of dementia was verified by autopsy in only $52.6 \%$ of dementia cases, resulting in a certain degree of subtype misclassification. However, the agreement rate between clinical diagnosis and neuropathologic diagnosis in our autopsy cases was $78.3 \%$ for all dementia, $84.8 \%$ for $\mathrm{AD}$, and $88.3 \%$ for $\mathrm{VaD}$, and thus the effect of this limitation, if any, would be modest. Finally, we could not estimate cognitive impairments during follow-up before the onset of dementia, although such impairments would be strongly associated with functional disability. Further studies should be conducted to estimate the cumulative incidence of moderate to severe cognitive impairment in order to prevent functional impairment in the elderly.

The present study demonstrated that lifetime risk of all dementia for Japanese elderly was substantial at $50 \%$ or higher. These findings suggest that the lifetime burden attributable to dementia in contemporary Japanese communities is immense. These findings will be helpful for policy makers in evaluating the impact of various policies and prioritizing research expenditures. Further investigations of the lifetime risk of dementia should be performed among geographically or ethnically diverse populations and repeated periodically in order to assist health economic and public policy decisions.

\section{Acknowledgment}

The authors thank the residents of Hisayama for their participation in the survey and the staff of the Division of Health and Welfare of Hisayama for their cooperation with this study; and Professor Yoshinao Oda, Professor Toru Iwaki, and their colleagues in the Department of Anatomic Pathology and Department of Neuropathology, Graduate School of Medical Sciences, Kyushu University, who provided insight and expertise on the autopsy findings.

\section{Study funding}

This study was supported in part by Grants-in-Aid for Scientific Research (A) (JP16H02644, and JP16H02692) and (B) (JP16H05850, JP16H05557, JP17H04126, and JP18H02737) and (C) (JP16K09244, JP17K09114, JP17K09113, JP17K01853, JP18K07565, and JP18K09412) and (Early-Career Scientists) (JP18K17925, and JP18K17382) from the Ministry of Education, Culture, Sports, Science and Technology of Japan; by Health and Labour Sciences Research Grants of the Ministry of Health, Labour and Welfare of Japan (H29-JunkankitouIppan-003 and H30-Shokuhin-[Sitei]-005); and by the Japan Agency for Medical Research and Development (JP18dk0207025, JP18ek0210082, JP18gm0610007, JP18ek0210083, JP18km0405202, JP18ek0210080, and JP18fk0108075).

\section{Disclosure}

The authors report no disclosures relevant to the manuscript. Go to Neurology.org/N for full disclosures.

\section{Publication history}

Received by Neurology April 13, 2019. Accepted in final form January 9, 2020.

\begin{tabular}{|c|c|c|}
\hline Name & Location & Contribution \\
\hline $\begin{array}{l}\text { Daigo } \\
\text { Yoshida, PhD }\end{array}$ & $\begin{array}{l}\text { Kyushu } \\
\text { University, } \\
\text { Fukuoka, Japan }\end{array}$ & $\begin{array}{l}\text { Study concept and design, data } \\
\text { collection, endpoint adjudication, } \\
\text { statistical analysis, interpretation } \\
\text { of data, writing of the } \\
\text { manuscript }\end{array}$ \\
\hline $\begin{array}{l}\text { Tomoyuki } \\
\text { Ohara, MD, } \\
\text { PhD }\end{array}$ & $\begin{array}{l}\text { Kyushu } \\
\text { University, } \\
\text { Fukuoka, Japan }\end{array}$ & $\begin{array}{l}\text { Data collection, endpoint } \\
\text { adjudication, interpretation of data }\end{array}$ \\
\hline $\begin{array}{l}\text { Jun Hata, MD, } \\
\text { PhD }\end{array}$ & $\begin{array}{l}\text { Kyushu } \\
\text { University, } \\
\text { Fukuoka, Japan }\end{array}$ & $\begin{array}{l}\text { Data collection, endpoint } \\
\text { adjudication, interpretation of data }\end{array}$ \\
\hline $\begin{array}{l}\text { Mao Shibata, } \\
\text { MD, PhD }\end{array}$ & $\begin{array}{l}\text { Kyushu } \\
\text { University, } \\
\text { Fukuoka, Japan }\end{array}$ & $\begin{array}{l}\text { Data collection, endpoint } \\
\text { adjudication, interpretation of data }\end{array}$ \\
\hline $\begin{array}{l}\text { Yoichiro } \\
\text { Hirakawa, } \\
\text { MD, PhD }\end{array}$ & $\begin{array}{l}\text { Kyushu } \\
\text { University, } \\
\text { Fukuoka, Japan }\end{array}$ & $\begin{array}{l}\text { Data collection, endpoint } \\
\text { adjudication, interpretation of data }\end{array}$ \\
\hline $\begin{array}{l}\text { Takanori } \\
\text { Honda, PhD }\end{array}$ & $\begin{array}{l}\text { Kyushu } \\
\text { University, } \\
\text { Fukuoka, Japan }\end{array}$ & $\begin{array}{l}\text { Data collection, endpoint } \\
\text { adjudication, interpretation of data }\end{array}$ \\
\hline $\begin{array}{l}\text { Yoshihiko } \\
\text { Furuta, MD, } \\
\text { PhD }\end{array}$ & $\begin{array}{l}\text { Kyushu } \\
\text { University, } \\
\text { Fukuoka, Japan }\end{array}$ & $\begin{array}{l}\text { Data collection, endpoint } \\
\text { adjudication, interpretation of data }\end{array}$ \\
\hline $\begin{array}{l}\text { Emi Oishi, MD, } \\
\text { PhD }\end{array}$ & $\begin{array}{l}\text { Kyushu } \\
\text { University, } \\
\text { Fukuoka, Japan }\end{array}$ & $\begin{array}{l}\text { Data collection, endpoint } \\
\text { adjudication, interpretation of data }\end{array}$ \\
\hline $\begin{array}{l}\text { Satoko } \\
\text { Sakata, MD, } \\
\text { PhD }\end{array}$ & $\begin{array}{l}\text { Kyushu } \\
\text { University, } \\
\text { Fukuoka, Japan }\end{array}$ & $\begin{array}{l}\text { Data collection, endpoint } \\
\text { adjudication, interpretation of data }\end{array}$ \\
\hline
\end{tabular}


Appendix (continued)

\begin{tabular}{|c|c|c|}
\hline Name & Location & Contribution \\
\hline $\begin{array}{l}\text { Shigenobu } \\
\text { Kanba, MD, } \\
\text { PhD }\end{array}$ & $\begin{array}{l}\text { Kyushu } \\
\text { University, } \\
\text { Fukuoka, Japan }\end{array}$ & $\begin{array}{l}\text { Endpoint adjudication, } \\
\text { interpretation of data }\end{array}$ \\
\hline $\begin{array}{l}\text { Takanari } \\
\text { Kitazono, MD, } \\
\text { PhD }\end{array}$ & $\begin{array}{l}\text { Kyushu } \\
\text { University, } \\
\text { Fukuoka, Japan }\end{array}$ & Interpretation of data \\
\hline $\begin{array}{l}\text { Toshiharu } \\
\text { Ninomiya, } \\
\text { MD, PhD }\end{array}$ & $\begin{array}{l}\text { Kyushu } \\
\text { University, } \\
\text { Fukuoka, Japan }\end{array}$ & $\begin{array}{l}\text { Principal investigator of the } \\
\text { Hisayama Study, securing of } \\
\text { funding sources, study concept and } \\
\text { design, statistical analysis, } \\
\text { interpretation of data, writing of the } \\
\text { manuscript }\end{array}$ \\
\hline
\end{tabular}

\section{References}

1. The World Alzheimer Report, 2015. The Global Impact of Dementia. Available at: alz. co.uk/research/WorldAlzheimerReport2015.pdf. Accessed August 31, 2019.

2. Wimo A, Guerchet M, Ali GC, et al. The worldwide costs of dementia 2015 and comparisons with 2010. Alzheimers Dement 2017;13:1-7.

3. Sayetta RB. Rates of senile dementia, Alzheimer's type, in the Baltimore Longitudinal Study. J Chronic Dis 1986;39:271-286.

4. Schoenberg BS, Kokmen E, Okazaki H. Alzheimer's disease and other dementing illnesses in a defined United States population: incidence rates and clinical features. Ann Neurol 1987;22:724-729.

5. Hagnell O, Ojesjo L, Rorsman B. Incidence of dementia in the Lundby Study. Neuroepidemiology 1992;11:61-66.

6. Hebert LE, Scherr PA, Beckett LA, et al. Age-specific incidence of Alzheimer's disease in a community population. JAMA 1995;273:1354-1359.

7. Seshadri S, Wolf PA, Beiser A, et al. Lifetime risk of dementia and Alzheimer's disease: the impact of mortality on risk estimates in the Framingham Study. Neurology 1997; 49:1498-1504.

8. Ott A, Breteler MM, van Harskamp F, Stijnen T, Hofman A. Incidence and risk of dementia: the Rotterdam Study. Am J Epidemiol 1998;147:574-580.

9. Lobo A, Lopez-Anton R, Santabarbara J, et al. Incidence and lifetime risk of dementia and Alzheimer's disease in a Southern European population. Acta Psychiatr Scand $2011 ; 124: 372-383$.

10. Mayeda ER, Glymour MM, Quesenberry CP, Whitmer RA. Inequalities in dementia incidence between six racial and ethnic groups over 14 years. Alzheimers Dement 2016;12:216-224.

11. Chene G, Beiser A, Au R, et al. Gender and incidence of dementia in the Framingham Heart Study from mid-adult life. Alzheimers Dement 2015;11:310-320.

12. Hata J, Ninomiya T, Hirakawa $Y$, et al. Secular trends in cardiovascular disease and its risk factors in Japanese: half-century data from the Hisayama Study (1961-2009). Circulation 2013;128:1198-1205.

13. Ninomiya T. Japanese legacy cohort studies: the Hisayama Study. J Epidemiol 2018; 28:444-451

14. Ohara T, Hata J, Yoshida D, et al. Trends in dementia prevalence, incidence, and survival rate in a Japanese community. Neurology 2017;88:1925-1932.

15. Yoshitake T, Kiyohara Y, Kato I, et al. Incidence and risk factors of vascular dementia and Alzheimer's disease in a defined elderly Japanese population: the Hisayama Study. Neurology 1995;45:1161-1168.

16. Matsui $\mathrm{Y}$, Tanizaki $\mathrm{Y}$, Arima $\mathrm{H}$, et al. Incidence and survival of dementia in a general population of Japanese elderly: the Hisayama Study. J Neurol Neurosurg Psychiatry 2009;80:366-370.

17. Hasegawa K, Inoue K, Moriya K. An investigation of dementia rating scale for the elderly [in Japanese]. Seishin Igaku 1974;16:965-969.

18. Imai $Y$, Hasegawa K. The Revised Hasegawa's Dementia Scale (HDS-R): evaluation of its usefulness as a screening test for dementia. J Hong Kong Coll Psychiatr 1994;4:20-24.
19. Folstein MF, Folstein SE, McHugh PR. "Mini-Mental State": a practical method for grading the cognitive state of patients for clinician. J Psychiatr Res 1975;12:189-198.

20. Ohmura T, Ueda K, Kiyohara Y, et al. Prevalence of type 2 (non-insulin-dependent) diabetes mellitus and impaired glucose tolerance in the Japanese general population: the Hisayama Study. Diabetologia 1993;36:1198-1203.

21. Bravo G, Hébert R. Age- and education-specific reference values for the Mini-Mental and modified Mini-Mental State Examinations derived from a non-demented elderly population. Int J Geriatr Psychiatry 1997;12:1008-1018.

22. American Psychiatric Association. Diagnostic and Statistical Manual of Mental Disorders, 3rd ed, revised. Washington, DC: American Psychiatric Association; 1987.

23. McKhann G, Drachman D, Folstein M, et al. Clinical diagnosis of Alzheimer's disease: report of the NINCDS-ADRDA Work Group under the auspices of Department of Health and Human Services Task Force on Alzheimer's disease. Neurology 1984;34 939-944.

24. Román GC, Tatemichi TK, Erkinjuntti T, et al. Vascular dementia: diagnostic criteria for research studies: report of the NINDS-AIREN International Workshop. Neurology 1993;43:250-260.

25. Fujimi K, Sasaki K, Noda K, et al. Clinicopathological outline of dementia with Lewy bodies applying the revised criteria: the Hisayama Study. Brain Pathol 2008;18 317-325.

26. The National Institute on Aging, and Reagan Institute Working Group on Diagnostic Criteria for the Neuropathological Assessment of Alzheimer's Disease. Consensus recommendations for the postmortem diagnosis of Alzheimer's disease. Neurobiol Aging 1997;18(suppl 4):S1-S2.

27. Mirra SS, Heyman A, McKeel D, et al. The Consortium to Establish a Registry for Alzheimer's disease (CERAD): part II: standardization of the neuropathologic assessment of Alzheimer's disease. Neurology 1991;41:479-486.

28. Braak H, Braak E. Neuropathological stageing of Alzheimer-related changes. Acta Neuropathol 1991;82:239-259.

29. McKeith IG, Dickson DW, Lowe J, et al. Diagnosis and management of dementia with Lewy bodies: third report of the DLB consortium. Neurology 2005;65:1863-1872.

30. Yamada M. Senile dementia of the neurofibrillary tangle type (tangle-only dementia), neuropathological criteria and clinical guidelines for diagnosis. Neuropathology 2003 ; 23:311-317.

31. Saito Y, Ruberu NN, Sawabe M, et al. Staging of argyrophilic grains: an age-associated tauopathy. J Neuropathol Exp Neurol 2004;63:911-918.

32. Tai BC, Machin D, White I, et al. Competing risks analysis of patients with osteosarcoma: a comparison of four different approaches. Stat Med 2001;20:661-684.

33. Shrout PE, Fleiss JL. Intraclass correlations: uses in assessing rater reliability. Psycho Bull 1979;86:420-428

34. World Health Organization. Life Table and Mortality Analysis/Chin Long Chiang. Geneva: World Health Organization; 1979. Available at: who.int/iris/handle/10665/ 62916. Accessed August 31, 2019.

35. Salmon JA, Wang H, Freeman MK, et al. Healthy life expectancy for 187 countries, 1990-2010: a systematic analysis for the Global Burden of Disease Study 2010. Lancet 2012;380:2144-2162.

36. Miyamoto M, Kodama C, Kinoshita T, et al. Dementia and mild cognitive impairment among non-responders to a community survey. J Clin Neurosci 2009;16:270-276.

37. Noguchi-Shinohara M, Yuki S, Dohmoto C, et al. Differences in the prevalence of dementia and mild cognitive impairment and cognitive functions between early and delayed responders in a community-based study of elderly. J Alzheimers Dis 2013;37: 691-698.

38. Gender Equality Bureau Cabinet Office of Japan. Women and Men in Japan 2017 Available at: gender.go.jp/english_contents/pr_act/pub/pamphlet/women-andmen17/pdf/1-3.pdf. Accessed August 31, 2019.

39. World Health Organization.Global Action Plan on the Public Health Response to Dementia 2017-2025. Geneva: World Health Organization; 2017.

40. Riedel BC, Thompson PM, Brinton RD. Age, APOE and sex: triad of risk of Alzheimer's disease. J Steroid Biochem Mol Biol 2016;160:134-147.

41. Farrer LA, Adrienne Cupples L, Haines JL, et al. Effects of age, sex, and ethnicity on the association between apolipoprotein $\mathrm{E}$ genotype and Alzheimer disease: a metaanalysis. JAMA 1997;278:1349-1356.

42. Altmann A, Tian L, Henderson VW, et al. Sex modifies the APOE-related risk of developing Alzheimer's disease. Ann Neurol 2014;75:563-573.

43. Sacco RL, Benjamin EJ, Broderick JP, et al. American Heart Association Prevention Conference: IV: prevention and rehabilitation of stroke: risk factors. Stroke 1997;28 1507-1517. 


\section{Neurology}

\section{Lifetime cumulative incidence of dementia in a community-dwelling elderly population in Japan \\ Daigo Yoshida, Tomoyuki Ohara, Jun Hata, et al.}

Neurology 2020;95;e508-e518 Published Online before print July 7, 2020

DOI 10.1212/WNL.0000000000009917

\section{This information is current as of July 7, 2020}

\section{Updated Information \&} Services

References

Subspecialty Collections

Permissions \& Licensing

Reprints including high resolution figures, can be found at: http://n.neurology.org/content/95/5/e508.full

This article cites 38 articles, 10 of which you can access for free at: http://n.neurology.org/content/95/5/e508.full\#ref-list-1

This article, along with others on similar topics, appears in the following collection(s):

\section{All Cognitive Disorders/Dementia}

http://n.neurology.org/cgi/collection/all_cognitive_disorders_dementia Alzheimer's disease

http://n.neurology.org/cgi/collection/alzheimers_disease

Cohort studies

http://n.neurology.org/cgi/collection/cohort_studies

Incidence studies

http://n.neurology.org/cgi/collection/incidence_studies

Vascular dementia

http://n.neurology.org/cgi/collection/vascular_dementia

Information about reproducing this article in parts (figures,tables) or in its entirety can be found online at:

http://www.neurology.org/about/about_the_journal\#permissions

Information about ordering reprints can be found online:

http://n.neurology.org/subscribers/advertise

Neurology ${ }^{\circledR}$ is the official journal of the American Academy of Neurology. Published continuously since 1951, it is now a weekly with 48 issues per year. Copyright Copyright ( 2020 The Author(s). Published by Wolters Kluwer Health, Inc. on behalf of the American Academy of Neurology.. All rights reserved. Print ISSN: 0028-3878. Online ISSN: 1526-632X.

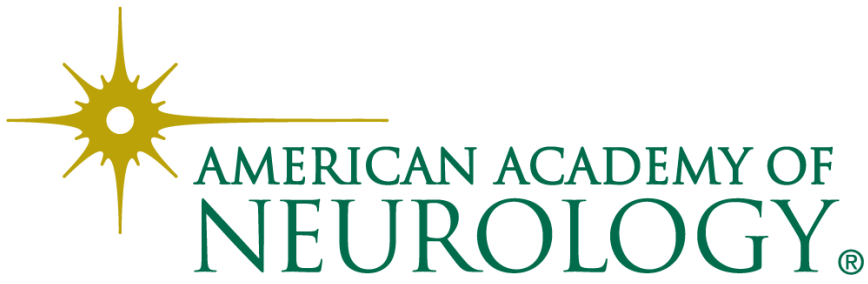

